\title{
The Application of FAR Transfer on Reconstruction of Urban Village
}

\author{
DAI Jian ${ }^{1, a}$, LV Fei ${ }^{2, b}$ and SUN Pingju ${ }^{3, c}$
}

${ }^{1}$ West Dazhi Street, No. 66, Box 1532, School of Architecture, Harbin Institute of Technology, China

${ }^{2}$ West Dazhi Street, No. 66, Box 1532, School of Architecture, Harbin Institute of Technology, China

${ }^{3}$ West Dazhi Street, No. 66, Box 1532, School of Architecture, Harbin Institute of Technology, China

adaijianII2004@126.com, 'bvfei@sina.com, 'sunpj031@163.com

Keywords: FAR Transfer, Urban Village Reconstruction, Overall Regeneration

Abstract. One of the most difficult thing in urban village reconstruction is to balance the interests among relevant parties, which often causes the phenomenon that the higher FAR in urban village reconstruction than it was before. Based on the FAR transfer and property rights exchange, the technology of FAR Transfer, which originally have been derived from American zoning reformation, is seen a new rebuilding idea in the Chinese urban village regeneration. In this article, we discuss the application of FAR Transfer Technology on urban village reconstruction from three aspects: building the rigid control and dynamic adjustment system, ensuring the FAR sending and receiving area, establishing the circulating platform.

\section{The Issues of Urban Village Regeneration}

Urban village regeneration is a supreme complicated system engineering, which is not achieved in one day. So we should hold the cautious attitude to recognize the key issues and choose the suitable modification methods. Currently the reconstruction of urban village is facing several difficulties:

\subsection{The Difficulty of Land Expropriation and Improvement Cost}

In the process of urban village reconstruction, farmers need some reasonable compensation through the ways of space displacement or relocation funds. Also, famers' property rights were protected by The Property Law, which published in 2007. For example, section 42 defined: "requisition any collectively-owned land should be paid enough compensation fee, including land compensation fee, resettlement compensation fee or compensation for ground attachments and green crops on the

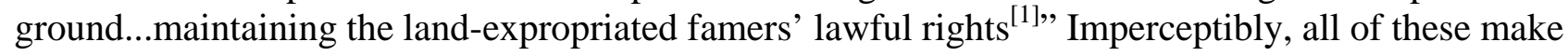
the government's financial pressure increase dramatically.

\subsection{The Dilemma of Balance between the Land Property Rights and Interest}

In China, land ownership system is a dual-pattern model, that is state ownership of land is undertaken in urban areas and collective ownership of land is implemented in rural areas. But the urban villages lie between "city" and "village", which special locations create the particularity of land ownership structures. The property relations within the urban villages are very complex, which bring more difficulty about checking property inventory and providing relocation compensation funds in transformation process. Meanwhile, How to coordinate the interest relationship between these subjects become the really tough tasks in the urban village regeneration process because the multiple parties would be involved in, such as municipal and district governments, village committees, indigenous villagers, foreign villagers, development organizations.

\subsection{High-Density Situation and Planning Predicaments}

Since the late 1990s, the agitation of houses retrofitting and scrambling appeared within the urban villages, which resulted in poor quality of the outer and inner environment, high building density, low level of public facilities and serious security hidden danger ${ }^{[2]}$. Viewed from the whole urban spatial pattern, the urban village is not involved in the land layout planning belonged to urban 
comprehensive planning because of the history reasons, so the overall space layout of urban village is embodied the features of "random" and "messy".

These issues above often plunge the urban village reconstruction into a dilemma: on one hand, if the environment quality is the primary factor, which means the great deal numbers of public spaces but the huge population and the super higher building denstiy in reality. On the other hand, if the development interest could be given the priority to make the planning scheme implemented, the FAR "Addition" principle for balancing the development interest should be obeyed firstly. But, the United States FAR management experience provides us a new direction. Thought of "floor area ratio transfer" could be introduced into the reconstruction schedule of urban village, transfer the FAR and balance the development interest at the same time, may be the important breakthrough to solve the practical difficulties of urban village reconstruction.

\section{The Features and Application Conditions of FAR Transfer Technology}

\subsection{The Concept and Operation Essentials of FAR Transfer}

Floor Area Ratio Transfer (being simplified to FAR transfer), originated from the American traditional zoning standardized rules, is an innovative method in order to improve the loneliness and similar housing patterns. The earliest thought of "transferable density from zoning" was presented by an American developer Gerald - Lloyd in 1961, which generally developed into the technology of Transfer Development Right (TDR), that means to remove some Floor Area Ratio from the resources areas to some other high density places, for compensating up the drawback of the "police power" of zoning.

The implication of FAR transfer need two places to realize, one is FAR limited building area called Sending Area, the other one is high-intensity area called Receiving Area. Sending area means some places with high history or landscape value should to be reserved, which represents the areas of a community that stakeholders wish to preserve and protect. Development potential (i.e. development rights) is transferred or 'sent' from the sending area to designated regions for development in that $\operatorname{area}^{[3]}$. Receiving area means some places with high development potential value could contain more intensive growth.

In the implementation process, the technology of FAR transfer emphasize the site moving and property rights exchange at the same time. When FAR trade begins, FAR in the sending area could be transferred to receiving area only after being converted into 'transfer credits' or 'development rights'. Similarly, the development rights or transfer credits in the receiving area could be used into city reconstruction. only after being converted into FAR back So the transfer credit is the important element to promote the FAR exchange between sending area and receiving area, which needs fair trade environment and mature market.

\subsection{The Technology of FAR Transfer Establish a Win-win Situation}

As known from the first part, the complicated questions of urban village regeneration can be attributed that the overall interests of reconstruction is very difficult to balance. For example, The practice of Shenzhen government handed the building removing and reconstructing of urban village to the market according to the market hierarchy of needs, for creating the fair competition situation. That means the developers pay the compensation of urban village demolition to relieve the government finance burden. But as the saying goes" Without a sheep, there can be no wool”, if the developers would like to invest a huge sum costs in the earlier stage, which definitely needs higher interest to get enough paying back at later stages. So until now, most of urban village reconstruction projects are holding higher intensity than before.

There are three merits of the technology of FAR transfer: the first one is to preserve the valuable spaces of cities. The FAR transfer can be an effective tool to preserve the valuable space or historical buildings to balance the contradiction between the development and conservation. The second one is this technology could transform the government management tools from regulatory style into market 
exchanging style, to benefit spaces resource reallocation ${ }^{[4]}$. The third one to deduce the urban sprawl through concentrating the urban development intensities. Therefrom, the technology of FAR transfer present a new idea, that is transferring the development potential set by the municipal to shape the city spaces and get the win-win situation, one is to balance the multiple interests, the other one is to optimize to environment quality. Therefore, in terms of urban village reconstruction, the characteristics and the key points of FAR transfer could be full used into practice, the thoughts of "FAR exchange" and "Property transaction" would be happened among different kinds of spaces according the market demand to realize the goal of reconstructing of space orders.

\section{China Could Construct a New Technology System of FAR Adjustment}

Following the competitive Chinese political and legal system developing, the city planning management system must trend to normalize, so we must present some reform rethinking to the further planning management. In the process of urban village renovation, the installation, adjustment and management of FAR would be based on macroscopic layer, and the technology of FAR transfer should be established into a new FAR adjustment system and operating multiple market methods, to obtain the goal of control but flexible, change but no mass ${ }^{[5]}$.

\subsection{Building the Rigid Control and Dynamic Adjustment System}

First of all, the urban village renovation is not only the technical issue, but also a policy question. On the aspect of technology, the further construction object should be predicted in more reasonable way; on the aspect of policy, the conflict of interest should be balanced. Only both of them to be realized at the same time, the FAR adjustment work of urban village could be proceeded. In that case, the FAR adjustment framework should be established into "Double-Restriction limitations"(Fig. 1), which means rigid control and dynamic adjustment. Under the rigid control limitation, the amount of development and resilience preservation should be guaranteed, reflected into the macro-level and middle-level. In the rigid control limitation, the integrated planning of urban village renovation should be protocoled into two layers on the base of evaluating the development intensity amount: the one the fundamental development standard control, which is the government planning regulation from top to bottom in according to the local planning goal, the other one is interest coordination control, which is interest group dynamic guiding from the bottom to top for balancing the conflictions of multiple subjects and increasing the strain capacity of FAR management. In the dynamic adjustment limitation, the FAR adjustment should be set by the specific land use and development conditions, reflected into micro-level. The two limitations work together to safeguard work of FAR management

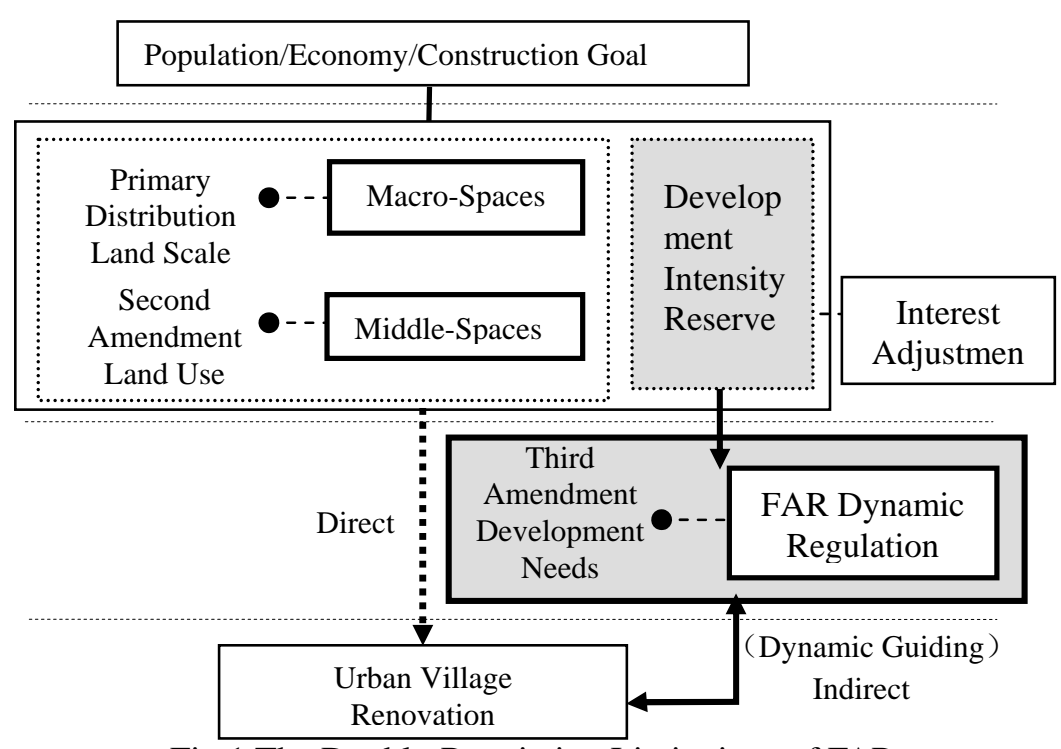

Fig.1 The Double-Restriction Limitations of FAR successfully. 


\subsection{Ensuring the FAR Sending Area and Receiving Area}

The next step is the FAR sending area and receiving area should be ensured in the process of urban-village regeneration. On the base of Double-Restriction limitations, the urban planners would choose the suitable zones to be the FAR sending area and receiving area by evaluating current developing intensity of urban village areas, delimiting the urban village quantities and ranges of implementation FAR regulation planning.

Some elements should be considered when choosing the sending area and receiving area of urban villages (Fig.2): the first element is the planning goal. Urban planning is to make a reasonable prediction for the urban future development, so the planning developing goal determine the urban village reconstruction functional orientation. For example, in the city of Shenzheng, one village called Dachong was located in the Shengzheng science park, so the main target people who are in the regeneration planning are scientific researchers, another Pinshan village was near the Shenzheng University town, so the main target people are teachers and students after planning regeneration; the third one called Yunong village is located in the Shenzheng port area, which faces the people of the tourists, the merchants and the Hong Kong residents. So the FAR of the three villages would be totally different after planning regeneration. The planning goal is the one of most important elements to be considered, which is the primary factor closely linked with urban-village economic location, surrounding environment and inner developing foundations. According to the urban land competitive bidding rental theorem, in the urban area, the development distribution of FAR presents space decline law, indicates developing intensity decreases from the urban center. Therefore, the different locational conditions of urban villages bring different improvement cost and totally diverse FAR.

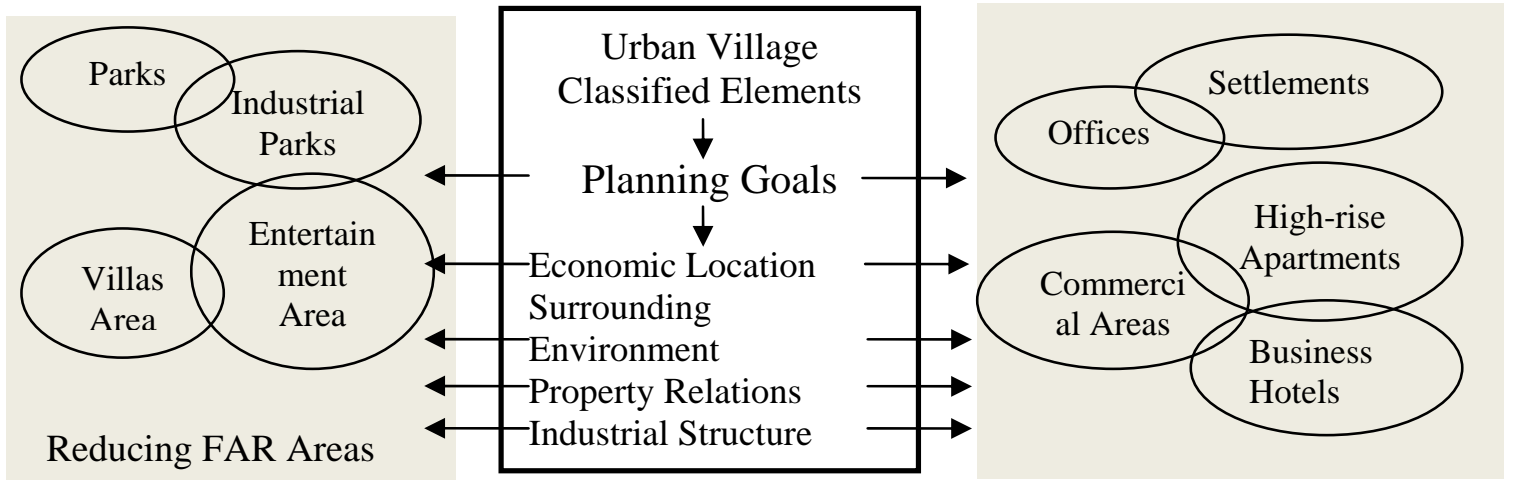

Fig. 2 The main factors to influence the classification of city village reconstruction

But the determination of FAR receiving areas are not only limited by the urban village scopes, the other places with high developing potential or the capability contains village surplus intensity storage also would be the options of FAR receiving areas, such as the future key development area in the urban planning developing strategy, or urban downtown commercial areas, office areas which can receive more developing intensity with good development foundations in the process of urban regeneration.

\subsection{Establishing the Circulating Platform between the Sending area and Receiving areas}

At last, building a dual circulating platform between FAR sending areas and FAR receiving areas. On the basis of ensuring the location of FAR sending area and receiving area(Fig.3). On one hand, to be the FAR sending area, the position of urban-villages is getting the lower the intensity after regeneration than before, which needs transform some of the FAR to other places. But due to the enormous upfront cost, getting balance between input and output is more difficult. On the other hand, as the construction zone, the FAR receiving area could contain higher intensity, which means the area could do more public contributions for people. The dual circulation platform is bundled the sending area and receiving area together, which could realize the two areas constructed the same time. On the dual circulating platform, the price of transferable FAR is decided by balance margin of the local land markets between sending and receiving areas. Or else, the American experience would be 
considered to build a "development credit” mechanism to maintain a kind of "laboratory securities", which determined by the government macroeconomic regulation and comprehensive planning.

Besides, the dynamic monitoring methods should be merged into the system, which means to supervise the FAR management system with the help of public strength and high-tech methods. Only borrowed from the public participation, the urban final goal would be realized, which is related to the key part of our country political restructuring ${ }^{[6]}$. The government could publicize the regulatory plan achievement on the website, the netizen could volunteer the public participation activity, and both ways would improve the government management more transparent. At meantime, the municipal authorities could renovate the illegal construction via some modern technologies, such as satellite supervising and field investigation.

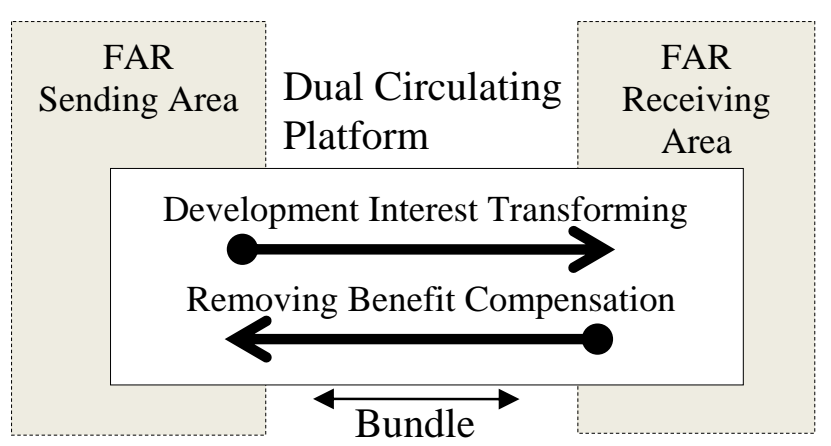

Fig. 3 The platform of FAR circulation established in city village regeneration

\section{Conclusion}

Before reform and opening, our country followed the former Soviet Union planning management mode, using the "Building Density" to represent the urban construction capacity. When the real estate developing, the FAR inherited the building density's technical attributes and developed a new mission of economic interest due to the change of economic system. In that case, some problems in the current the FAR management system appeared is inevitable. As the Qiu Baoxing pointed out that: "Under economic market, our work have to face more complicated situation in urban village planning management system.” Taking a panoramic view of the western developed country planning process, all are done in the process of correcting problems and amending the systems unceasingly. At present, our country is facing a new developing stage, the cities is undergoing from two-dimension land use planning to three-dimension space design, following the changing to the FAR management system to realize the dual goal of intensity control and quality guide.

\section{Acknowledgements}

This work was financially supported by The Research Fund for the Doctoral Program of Higher Education (20122302120060), HIT.NSRIF. (2013071) and HIT.NSRIF. (201656).

\section{References}

[1] Order of the President of the People's Republic of China, No.62, Article42. (2007), Information on http: //www.gov.cn/flfg/2007-03/19/content_554452.htm

[2] D. Anna. Shenzhen is Scrambling Illegal Constructions, One Night One Building. Dayoo-Guang Zhou Daily (2009), Information on http://news.qq.com/a/20091124/000211.htm

[3] P.L. Machemer, M.D. Kaplowitz, A framework for evaluating transferable development rights programmes. Journal of Environmental Planning and Management 45.6 (2002): 773-795.

[4] J. J. Costonis, "Development rights transfer: An exploratory essay." Yale Law Journal (1973): $75-128$.

[5] Ying C., Zhaohui W., Yanhua,Y. , Xiang S., Guangxu L., Formulation of Regulatory DE1-Ailed Planning: Exploration and Innovation. Urban Planning Review 3 (2007), p. 9-13

[6] Mingxiang Z., Li T., A Comparative Study of Development Control in U.K and U.S.A: Policy Implications for China. Shanghai Urban Planning Review 6 (2008), p. 18-22 